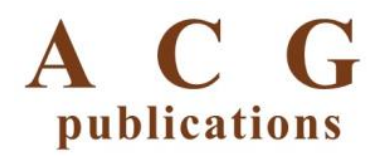

Org. Commun. 14:1 (2021) 92-96

organic

communications

\title{
Ultrasound-assisted efficient synthesis of 3-[4-(2-methoxyethyl) phenoxy] propane -1,2 -diol (Metoprolol EP impurity D)
}

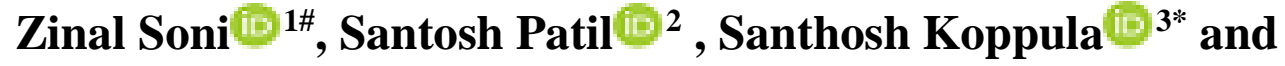 \\ Poonam Koppula $\oplus^{2}$ \\ ${ }^{1}$ School of Liberal Studies and Education, Navrachana University, Vadodara-391410 \\ ${ }^{2}$ Ipca Laboratories Ltd., Vadodara - 391445, India \\ ${ }^{3}$ School of Sciences, GSFC University, Vadodara, Gujarat, 391750, India
}

(Received October 11, 2020 ; Revised February 27, 2021; Accepted March 01, 2021)

\begin{abstract}
Safety of a drug molecule is dependent on various impurities formed during chemical process which may cause drug product instability, decreased product performance, loss in potency, and/or formation of potentially genotoxic impurities. Therefore, it is essential to identify and quantify the impurities generated during the drug development stage. Herein, we describe the synthesis and characterization of metoprolol EP Impurity D, 3-[4-(2methoxyethyl)phenoxy]propane-1,2-diol (1), reported in European Pharmacopeia. The synthesis of compound 1 was accomplished starting from 4-(2-methoxyethyl)phenol in two steps via $\mathrm{KOH}$-mediated substitution with epichlorohydrin and then $\mathrm{H}_{2} \mathrm{SO}_{4}$ catalyzed hydrolysis of the formed epoxide.
\end{abstract}

Keywords: Impurity D; Metoprolol; synthesis; characterization; ultrasonic waves; green chemistry. (02021 ACG Publication. All right reserved.

\section{Introduction}

Metoprolol is a selective $\beta 1$ receptor blocker and commonly used to treat high blood pressure, chest pain and a number of conditions involving an abnormally fast heart rate. ${ }^{1,2}$ It is chemically known as bis [(2RS)-1-[4- (2-methoxyethyl)phenoxy]-3-[(1-methylethyl)amino]propan-2-ol] $\quad$ (2R,3R)-2,3dihydroxybutanedioate having structure as shown in (Figure 1). The active ingredient in Metoprolol tartarate tablets is metoprolol, and lactose is one of the excipient which is used as a diluent. ${ }^{3 .}$

Regulatory authorities are doing careful examination of the safety profiles of drug substances. ${ }^{4,5}$ Impurity profiling in pharmaceuticals is now gaining critical attention for medical safety and drug effectiveness of API's. ${ }^{6,7}$ The "International Conference on Harmonisation of Technical Requirements for Registration of Pharmaceuticals for Human Use" has dedicated guidelines on impurities in new drug substances, products and residual solvents. ${ }^{8-10}$ Hence, there is a surge in demand for impurity reference standards by both regulatory authorities and pharmaceutical companies, as each impurity needs to be quantified in the drug substance. ${ }^{11}$ To our knowledge, there are two records in the literature describing methodologies for the synthesis of EP impurity D. Cohnen synthesized EP impurity D by a combination of 4-(2-methoxyethyl)phenol and 2-oxiranemethanol. ${ }^{12}$ The synthesis described by Gurjar et al. ${ }^{13}$ proceeds via $O$-allylation of 4-(2-methoxyethyl)phenol followed by $\mathrm{OsO}_{4}$-catalyzed hydroxylation of

\footnotetext{
* Corresponding author: E-Mail: ksk.india@gmail.com

\#The author is presently associated with Sun Pharmaceutical Industries Ltd. Vadodara- 390012

The article was published by ACG Publications

http://www.acgpubs.org/journal/organic-communications @ January-March 2021 EISSN:1307-6175

DOI: http://doi.org/10.25135/acg.oc.98.20.10.1844
} 
alkene double bond. Here we present an alternative synthesis for EP impurity D via 4-(2methoxyethyl)phenol and epichlorohydrin.

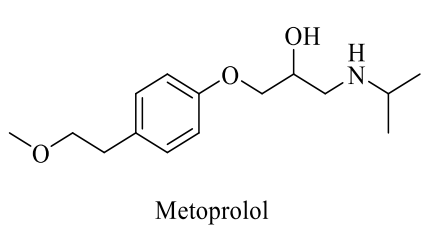<smiles>CC(C)NCC(O)COc1ccc(C=O)cc1</smiles>

EP impurtiy C / USP related compund C<smiles>CC(C)NCC(O)COc1ccccc1</smiles>

EP impurity F<smiles>CCNCC(O)COc1ccc(CCOC)cc1</smiles>

EP impurity A / USP related compund A<smiles>COCCc1ccc(O)cc1</smiles>

EP impurity B<smiles>COCCc1ccc(OCC(O)COCC(O)CNC(C)C)cc1</smiles>

EP impurity $\mathrm{J}$<smiles>COCCc1ccc(OCC(O)CO)cc1</smiles>

EP impurity D<smiles>COCCc1ccccc1OCC(O)CNC(C)C</smiles>

EP impurity E<smiles>OCCc1ccc(O)cc1</smiles><smiles>CC(C)NCC(O)COc1ccc(CCO)cc1</smiles><smiles>CC(C)NCC(O)CNC(C)C</smiles>

EP impuriy M<smiles>CC(C)NCC(O)CO</smiles>

EP impurity N<smiles>COCCc1ccc(OCC(O)CN(CC(O)COc2ccc(CCOC)cc2)C(C)C)cc1</smiles>

EP impurity O / USP related compound D<smiles>COCCc1ccc(OCC(O)CCl)cc1</smiles>

USP related compound B

Figure 1. Metoprolol and its pharmacopoeia impurities

\section{Background}

United States Pharmacopoeia includes four impurities i.e related compounds A-D and European Pharmacopoeia has A-O impurities as listed in Figure 1. Many researchers have worked on impurity profiling of metoprolol and hence, on their analytical method development.

In recent years, green chemistry approaches have gained importance in synthetic organic chemistry not only for reduction of byproducts, reduction of waste products and lowering of energy costs but also in the development of new methods / methodologies. ${ }^{14,15}$ Medicinal and pharmaceutical industries traditionally have large volume of waste/product ratio when compared with other existing areas of chemistry ${ }^{16,17}$ and hence, most promising for evolution of greener methods.

Out of the pharmacopoeia impurities, metoprolol EP impurity D is a by-product formed during the synthesis of metoprolol API at levels between 0.2-0.3\%. International Conference on Harmonization (ICH) has recommended guidelines to qualify the drug substance. As the metoprolol EP impurity D is a by-product, it would be required in essential quantity for method development, validation and qualification of API. 


\section{Synthesis of Metoprolol EP impurity}

To the best of our knowledge, there is no reported synthesis of metoprolol EP impurity D utilizing green chemistry approaches in literature and herein, we wish to report a short synthesis of metoprolol EP impurity D for impurity profile study of metoprolol API which will help pharmaceutical companies all over the world to have better control on the process and routine batch analysis.

The newly developed method utilizes ultrasonic waves as source of energy to carry out reaction at room temperature. Water is used as solvent for the reaction. The developed method avoids use of any dangerous reagents and expensive catalysts, reduces the time of reaction required to obtain the product with high yield and purity.

\section{Experimental}

The detailed experimental procedure is given as supplementary information of the article.

\section{Present Study}

Synthesis of EP impurity D (Scheme 1) started from commercially available 4-(2methoxyethyl)phenol (2) and epichlorohydrin (3). In a typical general experimental procedure, a solution of $\mathbf{2}$ and $\mathbf{3}$ in solvent in presence of $\mathrm{KOH}$ was stirred at room temperature till completion of reaction, resulting in the formation of 3-[4-(2-methoxyethyl)phenoxy]-1,2-epoxy propane (4). The excess of $\mathbf{3}$ was distilled out under vacuum and the reaction mass was extracted with $\mathrm{CH}_{2} \mathrm{Cl}_{2}$. Distillation of $\mathrm{CH}_{2} \mathrm{Cl}_{2}$ layer gives intermediate $\mathbf{4}$ as brown color oil (51\%).

The final product was obtained by reaction of 3 with $98 \% \mathrm{H}_{2} \mathrm{SO}_{4}$ in appropriate solvent by stirring the reaction mixture at ambient temperature till completion of reaction. The reaction mixture on extraction with $\mathrm{CH}_{2} \mathrm{Cl}_{2}$ and then further distillation of $\mathrm{CH}_{2} \mathrm{Cl}_{2}$ layer afforded crude EP impurity D (1). Purification of crude product with column chromatography (60-120 mesh silica gel and petroleum etherethyl acetate in the ratio 95:5) yielded 63\% of EP impurity D (1).

To study the generality of synthetic route, several trials of this novel and general method were conducted and results are summarized in (Table 1 and 2).<smiles>COCCc1ccc(O)cc1</smiles>

Scheme 1. Preparation of metoprolol EP impurity D (Reaction conditions are given in Tables 1and 2

Table 1. Reaction condition of key compound 4

\begin{tabular}{cccccccc}
\hline Entry & Amount of KOH & \multicolumn{2}{c}{ MeOH as solvent } & \multicolumn{2}{c}{$\mathbf{H}_{2} \mathbf{O}$ as solvent } & \multicolumn{2}{c}{ Ultrasound assisted $^{\mathbf{a}}$} \\
\hline & & Yield & Time $(\mathrm{h})$ & Yield $(\%)^{\mathrm{b}}$ & Time (h) & Yield (\%) & Time (min) \\
& & $(\%)^{\mathrm{b}}$ & & & & & \\
\hline 1 & 0.5 molar equiv. & 22 & 20 & 31 & 18 & 43 & 90 \\
2 & 1.0 molar equiv. & 28 & 20 & 38 & 18 & 51 & 90 \\
\hline
\end{tabular}

aReaction condition: 2 (1.0 molar equiv.), 3 (1 molar equiv.), $\mathrm{KOH}\left(1.0\right.$ molar equiv.) in $\mathrm{H}_{2} \mathrm{O}(15 \mathrm{~mL})$, irradiated with

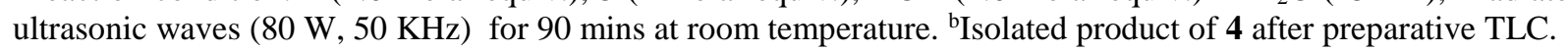

Table 2. Reaction condition of EP Impurity D

\begin{tabular}{cccccccc}
\hline Entry & Amount of $\mathbf{H}_{2} \mathbf{S O}_{4}$ & \multicolumn{2}{c}{ Methanol as solvent } & \multicolumn{2}{c}{$\mathbf{H}_{2} \mathbf{O}$ as solvent } & \multicolumn{2}{c}{ Ultrasound assisted $^{\mathrm{a}}$} \\
\hline & & ${\text { Yield }(\%)^{\mathrm{b}}}^{\mathrm{b}}$ & Time $(\mathrm{h})$ & ${\text { Yield }(\%)^{\mathrm{b}}}^{\mathrm{T}}$ & Time (h) & Yield $(\%)^{\mathrm{b}}$ & Time (min) \\
\hline 1 & 0.05 equivalent & 28 & $5-6$ & 46 & 5 & 51 & 30 \\
2 & 0.1 equivalent & 34 & $5-6$ & 48 & 5 & 63 & 30 \\
\hline
\end{tabular}

a Reaction condition: 4 (1 equiv.), acid (0.1 equiv.) in water $(5 \mathrm{~mL})$ irradiated with ultrasonic waves $(80 \mathrm{~W}, 50 \mathrm{KHz})$ for 30 mins at room temperature. ${ }^{b}$ Isolated product of $\mathbf{1}$ after column chromatography. 
Use of 1.0 equivalent of $\mathrm{KOH}$ is sufficient to push the reaction in forward direction. Higher amounts of $\mathrm{KOH}$ did not improve the result. For ring opening of epoxide, $\mathrm{NaOH}$ was first tested but no reaction occurred. Addition of 0.1 equivalent of $\mathrm{H}_{2} \mathrm{SO}_{4}$ was able to open the epoxide ring to afford the diol 1.

To lower the utilization of environmentally harmful solvents, we choose to carry out the reaction in $\mathrm{H}_{2} \mathrm{O}$ as it is recognized as an attractive medium for many organic reactions. ${ }^{18}$ Synthesis of EP impurity D (1) using $\mathrm{H}_{2} \mathrm{O}$ as a solvent showed a significant improvement on the yield of isolated product ranging from $58-63 \%$.

To further incorporate the principles of green chemistry, the optimized process was performed in presence of ultrasonic waves which led to drastic reduction of time required for completion of reaction.

The optimized process was also adopted for reaction in microwave but it led to high exothermicity during course of reaction resulting in large number of side products.

The ultrasound assisted reaction conditions afforded good yield of the key intermediate $\mathbf{4}$ as well as EP impurity D (1) during the course of this study and in majority of trials, the greener approaches generated EP impurity $\mathrm{D}$ of high purity.

EP Impurity D was characterized by spectroscopy $\left({ }^{1} \mathrm{H}\right.$ NMR, ${ }^{13} \mathrm{C}$ NMR and Mass) studies; and the ${ }^{1} \mathrm{H}$ NMR spectral data were found to be comparable with the reported literature. ${ }^{13}$

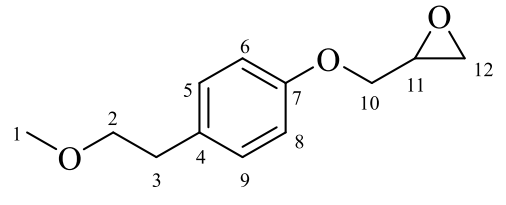

4

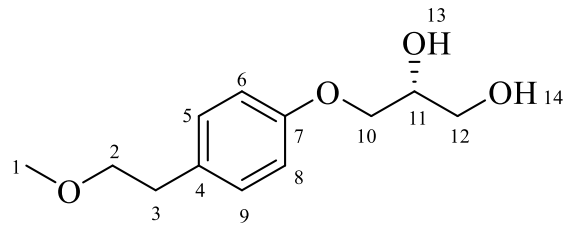

1

3-[4-(2-Methoxyethyl)phenoxy]-1,2-epoxy propane (4): Pale brown oil; yield: 51\%; IR ( $\left.\mathrm{KBr}, \mathrm{v}_{\max }, \mathrm{cm}^{-1}\right)$ :

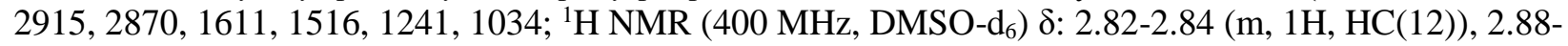
2.92 (m, 2H, $\left.\mathrm{H}_{2} \mathrm{C}(3)\right)$, 2.96-3.03 (m, 1H, $\left.\mathrm{HC}(12)\right)$, 3.23 (s, 3H, OMe), 3.45-3.49 (m,1H, HC(19)), 3.58$3.62\left(\mathrm{~m}, 2 \mathrm{H}, \mathrm{H}_{2} \mathrm{C}(2)\right)$, 3.83-3.88 (m, $\left.1 \mathrm{H}, \mathrm{H}_{2} \mathrm{C}(10)\right)$, 4.42-4.48 (m, 1H, $\left.\mathrm{HC}(10)\right)$, 6.83-6.85 (AA' part of AA'BB' system, quasi d, $J=9 \mathrm{~Hz}, 2 \mathrm{H}, \mathrm{HC}(5)$ and $\mathrm{HC}(9)$ ), 7.13-7.16 (BB' part of AA'BB' system, quasi d, $J=9 \mathrm{~Hz}, 2 \mathrm{H}, \mathrm{HC}(6)$ and $\mathrm{HC}(8))$ ppm; Elemental analysis: calcd $(\%)$ for $\mathrm{C}_{12} \mathrm{H}_{16} \mathrm{O}_{3}: \mathrm{C}, 69.23 ; \mathrm{H}, 7.69$; found: C, 69.46; H, 7.85; MS: $m / z[\mathrm{M}+1]^{+} 209.18$.

3-[4-(2-Methoxyethyl)phenoxy]propane-1,2-diol (1): Pale yellow oil; yield: $63 \%$; IR $\left(\mathrm{KBr}, v_{\max }, \mathrm{cm}^{-1}\right)$ : 3473 - 3313 (Broad peak), 2929, 2878, 1610, 1513, 1246, 1039: ${ }^{1} \mathrm{H}$ NMR (400 MHz, DMSO-d 6 ) $\delta: 2.72-$ 2.80 (t, $\left.2 \mathrm{H}, \mathrm{H}_{2} \mathrm{C}(3)\right), 3.21$ (s, 3H, $\left.\mathrm{OCH}_{3}\right), 3.54-3.82$ ((m, 6H, $\left.\mathrm{H}_{2} \mathrm{C}(2), \mathrm{H}_{2} \mathrm{C}(10), \mathrm{H}_{2} \mathrm{C}(12)\right)$, 3.94-4.04 $(\mathrm{m}, 1 \mathrm{H}, \mathrm{HC}(11)), 4.70-4.85$ (br s, $1 \mathrm{H}, \mathrm{OH}), 6.82-6.85$ (AA' part of AA'BB' system, quasi d, $J=9 \mathrm{~Hz}$, $\mathrm{HC}(5)$ and $\mathrm{HC}(9))$, 7.15-7.19 (BB' part of AA' BB' system, quasi d, $J=7.5, \mathrm{HC}(6)$ and $\mathrm{HC}(8)$ ), ) ppm. ${ }^{13} \mathrm{C}$ NMR (100 MHz, DMSO-d $\left.\mathrm{d}_{6}\right): \delta=162.4(\mathrm{C}(7))$, 135. $(\mathrm{C}(4)), 129.4(\mathrm{C}(5)$ and $(\mathrm{C}(9)), 115.71(\mathrm{C}(6)$ and $(\mathrm{C}(8)))$, $73.6(\mathrm{C}(2)), 69.8(\mathrm{C}(10)), 63.7(\mathrm{C}(12)), 70.6(\mathrm{C}(11)), 60.6(\mathrm{C}(1)), 37.9(\mathrm{C}(7))$ ppm; Elemental analysis: calcd (\%) for $\mathrm{C}_{12} \mathrm{H}_{18} \mathrm{O}_{4}$ : C, 63.71; H, 7.96; found: $\mathrm{C}, 64.06 ; \mathrm{H}, 7.92 ; \mathrm{MS}: \mathrm{m} / z[\mathrm{M}+1]^{+} 227.51$.

\section{Conclusion}

In conclusion, we have developed a conveniently efficient and ultrasound-assisted, environment-friendly synthesis of metoprolol EP impurity D with an overall yield of 63\%; and in high purity via HPLC $(97.8 \%)$.

\section{Supporting Information}

Supporting information accompanies this paper on http://www.acgpubs.org/journal/organiccommunications 
Synthesis of Metoprolol EP impurity

\section{ORCID}

Zinal Soni: $0000-0003-4886-605 \mathrm{X}$

Santosh Patil: 0000-0002-3134-0070

Santhosh Koppula: 0000-0002-8334-2350

Poonam Koppula: 0000-0001-6766-327X

\section{References}

[1] Saddique, F.A; Zahoor, A.F; Yousaf, M.; Irfan, M.; Ahmad, M.;Mansha, A.; Khan, Z.A.; Naqvi, S.A.R. Synthetic approaches towards the synthesis of beta-blockers (betaxolol, metoprolol, sotalol, and timolol). Turk. J. Chem. 2016, 40, 193-224.

[2] Hoffman, B.B. In Basic and Clinical Pharmacology; Katzung, B. G., Ed., 7th ed. Appleton-Lange: Stamford, CT, USA, 1998, 136-151.

[3] Reddy, R.B;, More, K.R, Gupta, L.; Jha, M.S.; Magar, L. Identification, synthesis, isolation and characterization of new impurity in metoprolol tartarate tablets. J. Pharm. Biomed. Anal., 2016, 117, 104108.

[4] Ye, Q.; Huang, Y.; Rusowicz, A.; Palaniswamy, V.A.; Raglino, T.V. Understanding and controlling the formation of an impurity during the development of muraglitazar, a PPAR dual agonist. Org. Process. Res. Dev. 2010, 14, 238-224.

[5] Kadivara, M.H.; Sinha, P.K.; Kushway, D.; Jana, P.; Sharma, H.; Bapodra, A. Study of impurity carryover and impurity profile in Febuxostat drug substance by LC-MS/MS technique. J. Pharm. Biomed. Anal., 2011, 56, 749-757.

[6] Gorog, S. New safe medicines faster: the role of analytical chemistry. Trends Anal. Chem. 2003, 22, 407415.

[7] Bartos, D; Gorog, S. Recent advances in the impurity profiling of drugs. Curr. Pharm. Anal. 2008, 4, 215230.

[8] Internation Conference on Harmonization (ICH) Guidelines, Q3A (R2): Impurities in New Drug Substances, March, 2020. Accessed 20 September 2020

[9] Internation Conference on Harmonization (ICH) Guidelines, Q3B (R2): Impurities in New Drug Products, March, 2020. Accessed 20 September 2020

[10] Internation Conference on Harmonization ( $\mathrm{ICH})$ Guidelines, Q3C (R8): Impurities guidelines for residual solvents. March, 2020. [Accessed 20 September 2020].

[11] Pramanik, C; Bhumkar, R.; Karhade, G.; Khairnar, P.; Primaty, N.K.; Gurjar, M.K. Efficient synthesis of impurity-C of antimigraine agent rizatriptan benzoate. Org. Process Res. Dev. 2012, 16, 507-511.

[12] Cohnen, E. Substituted phenoxyalkanolamines and phenoxyalkanolcycloalkylamines, their pharmaceutical compositions and their intermediates x Eur. Pat. Appl. 82461, 29 Jun 1983.

[13] Gurjar, M K; Joshi, V S; Sastry, B S; Rama Rao, A V. A new route to ( \pm ) Metoprolol. Synth. Commun. 1990, 20, 3489-3496.

[14] Cave, G W V; Raston, C L. Scott, J. Recent advances in solventless organic reactions: towards benign synthesis with remarkable versatility. Chem. Commun. 2001, 2159-2169.

[15] Bose, D S; Fatima, L. Mereyala, H.B. Green chemistry approaches to the synthesis of 5-alkoxycarbonyl-4aryl-3,4-dihydropyrimidin-2(1H)-ones by a three-component coupling of one-pot condensation reaction: comparison of ethanol, water, and solvent-free conditions. J. Org. Chem. 2003, 68, 587-590.

[16] Sheldon, R.A. The E factor 25 years on: the rise of green chemistry and sustainability. Green Chem. 2017, $19,18-43$

[17] Tobiszewski, M; Marc, M.; Galuszka, A.; Namiesnik, J. Green chemistry metrics with special reference to green analytical chemistry. Molecules 2015, 20, 10928-10946.

[18] Sachdeva, H; Khaturia, S. A mini-review on organic synthesis in water. MOJ Bioorg. Org. Chem., 2017, 1, 239-243.

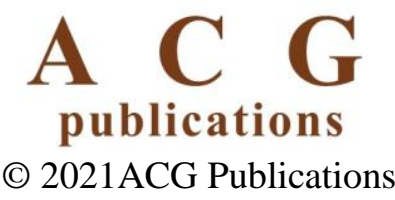

